\title{
Qualitative and sensory characterization of muffins synthesized with chestnut flour substitution
}

\author{
Anum Nazir ${ }^{1,2^{*}}$, Nizwa Itrat ${ }^{1,2}$, Maham Mehboob ${ }^{1,}$ Uswa Ahmad $^{3}$ and Dua \\ Ali $^{1}$ \\ 1. Department of Nutrition and Dietetics, University of Faisalabad, 38000, Punjab, Pakistan \\ 2. Department of Nutritional Science, Government College University Faisalabad Punjab, Pakistan \\ 3. School of Human Nutrition and Dietetics, Minhaj University Lahore, Pakistan \\ *Corresponding author's email: Anum.nazir@tuf.edu.pk
}

Citation

Anum Nazir, Nizwa Itrat, Maham Mehboob, Uswa Ahmad and Dua Ali. Qualitative and sensory characterization of muffins synthesized with chestnut flour substitution. Pure and Applied Biology. Vol. 11, Issue 3, pp762-772. http://dx.doi.org/10.19045/bspab.2022.110077

\begin{tabular}{llll}
\hline \hline Received: 21/08/2021 & Revised: 30/10/2021 & Accepted: 13/11/2021 & Online First: 18/11/2021 \\
\hline
\end{tabular}

\section{Abstract}

Celiac disease is being known as inflammation of small intestine and depicted by enteropathy of gluten sensitivity. Chestnut is one of effective fruit for the treatment of this disease. It has gluten free properties. Water Chestnut (Trapa Natans) belongs to the family of Trapaceae. Trapa fruits are astringent, diuretic sweet and tonic. The fruit of chestnut contains vitamin B, vitamin A and C, and minerals. The current research work was planned to determine the nutritional profile of dried water chestnut. Dried chestnut grinded into flour was analyzed for proximate analysis. Mineral profile was determined by using flame photometer sodium and potassium. Results of proximate analysis displayed that among all the observed minerals, sodium and potassium were the most abundant i.e. 1.4 and $0.9 \mathrm{mg}$, correspondingly. Five muffins products i.e. $\mathrm{T}^{\circ}(0 \mathrm{~g}), \mathrm{T}_{1}(4 \mathrm{~g}), \mathrm{T}_{2}(6$ $\mathrm{g}), \mathrm{T}_{3}(8 \mathrm{~g}), \mathrm{T}_{4}(10 \mathrm{~g})$ and $\mathrm{T}_{5}(12 \mathrm{~g})$ were prepared by different substitutions of chestnut flour. Mean values of sensory evaluation of prepared products (muffins) for the appearance feature, amalgamated with chestnut flour. Results of muffins appearance parameter showed that treatments $\mathrm{T}_{4}$ and $\mathrm{T}_{5}$ enhanced the parameter greatly compared to other treatments. Overall results depicted that $\mathrm{T}_{5}$ was the most effective in case of flavor, aroma, softness and overall acceptability of the prepared muffins while $T_{4}$ was the most effective in case of rest of the qualitative paramters of the muffins. Therefore, addition of chestnut flour can enhanced the qualitative aspects of the prepared bakery products and attraction of the consumer as well leading to the acceptance of the products. The data attained for all parameters was monitored statistically.

Keywords: Aroma; Flavor; Muffins; Qualitative paramters; Softness

\section{Introduction}

Non-traditional food sources and their value addition have received a lot of interest in recent years due to their potential usage as functional components in meal compositions. Functional food is defined as food or a dietary component that has a positive physiological effect on human health and lowers the risk of sickness. The positive benefits of functional food might be shown over a lengthy time of consumption [1]. Several research on non- 
gluten flour substitution for wheat flour in flour-based confectionary products discovered that rice and chestnut flour in correct proportions are ideal tailor-made mixes for the creation of gluten-free or gluten-reduced food items [2].

Water chestnut (Trapa Natans) in (Hindi) is singhara and simkhata, or in (Malyalam) vankottakkaya and karimbolam belonging Trapaceae family, Rosidae subfamily, Magnoliopsida class or Magnoliphyta division. Singhara is highly nutritive but this fruit lost his importance because singhara is available in year just for 2-3 months. Trapa fruits are astringent, diuretic sweet and tonic [3]. Singhara found in world tropical, temperate or sub-tropical zones, Europeans ancient used singhara frequently like food. Singhara is found in slow-moving lakes, ponds, and marshes, and it is commonly collected in Asia [3]. Water chestnut species Trapa bispinosa and Trapa quadrispinosa are commonly farmed in India. In Asian nations, the plant has been grown for its nutritious seeds, with the fruits eaten raw, boiled, or roasted, and the stems and leaves eaten raw or cooked as vegetables. The fruit of the water chestnut is a nut with both nutritional and therapeutic qualities [4]. Dried kernels are sold as nuts and flour for muffins, breads, chapatis, and other baked products. Chestnut fruit has a carbohydrate level equal to wheat and rice grains. The chestnut tree's fruit contains vitamins $\mathrm{B}, \mathrm{A}$, and $\mathrm{C}$, as well as minerals $(\mathrm{K}, \mathrm{Mg}, \mathrm{Fe}, \mathrm{Mn}, \mathrm{P}, \mathrm{Cu})$. It contains a lot of fibre and vital amino acids. Furthermore, there is a high antioxidant content, a low-fat content, and no cholesterol, all of which contribute to an increase in nutritional value and a good health effect [5, 6].

A subjective technique based on the use of human senses is used to evaluate the sensory characteristics of food products. Sensory analysis determines if a product is acceptable to the consumer. Various sensory qualities are examined for different food products, but typical sensory features include appearance, color, structure, mastication, and taste. Color and texture of food products can be determined instrumentally using a texture analyzer or a novel form of instrumental analysis utilizing a video meter.

Much examination has been directed on different chestnut parts, testing the physical and tangible qualities of biscuits created utilizing $0,40,50$, or $60 \%$ somewhat defatted soy flour instead of wheat flour. Nonconventional food sources and their worth expansion have gotten a ton of interest lately because of their likely utilization as utilitarian parts in supper synthesis. The impact of water chestnut on the synthetic, tactile, and healthful properties of wheatbased biscuits [7]. Biscuits arranged with a few flours (wheat, rice, oat, corn, and grain) were tried for cell reinforcement action and starch absorbability [8]. The researcher created fiber-rich biscuits. Notwithstanding, no methodical investigation of the use of water chestnut flour (WCF) and $\mathrm{BF}$ combinations in biscuit produce has been accounted for. Mixing BF with WCF, changing prebaking and post heating cycles, and subbing parts, for example, sugar with nonnutritive sugars seem, by all accounts, to be an incredible strategy for making diabetic biscuits [10].

When wheat flour was combined with starches from potato, cassava, and yam, the peak viscosity increased. As the amount of chestnut flour in the mix rose from 91.40 to $82^{\circ} \mathrm{C}$, the pasting temperature decreased noticeably. However, there is a scarcity of research on the impact of chestnut flour on the rheological characteristics of gluten-free cookies and muffins [11]. Keeping the foregoing in mind, the current study was carried out to analyze the qualitative and sensory assessment of water chestnut flour muffins. 


\section{Materials_and Methods}

The study was carried out in the department of dietetics and nutritional sciences at the University of Faisalabad, and the analysis was done in a post-graduate laboratory. Water chestnuts were obtained at the Faisalabad local market. Water chestnut flour (Trapa natans) was purchased locally, sieved to remove contaminants, and kept in an airtight container until needed. We got sugar powder, shortening (margarine), baking powder, eggs, and vanilla extract from the neighborhood store. In a grinder, water chestnuts were dried and crushed into flour. The powder was packed in an airtight polyethene bag to keep contamination at bay until further use. Wheat flour (WF) was substituted with water chestnut flour (WCF) at $25 \%, 35 \%, 45 \%$, and $55 \%$ to create the following blends: $25 \% \mathrm{WCF}, 35 \% \mathrm{WCF}$, $45 \% \mathrm{WCF}$, and $55 \% \mathrm{WCF}$.

The prepared muffins were tested for proximate components and mineral (sodium and potassium) content using the techniques described above. In phase of product development muffins with diverse levels of water chestnut flour were prepared. Sensory Attributes were followed according to 9point Hedonic Scale. Color, appearance, texture, flavor, softness, mouth feel, after taste and Overall acceptability

The biscuits' tone was estimated multiple times with Hunter Lab's shading estimation gear (Model Lab filter, XE, Reston, VA, USA). The shading scales $L$, $a$, and $b$ were utilized, with $\mathrm{L}$ addressing gentility, an addressing shading power from green to red, and $b$ addressing shading force from blue to yellow. DE was determined utilizing the shading distinction between the biscuit and the control biscuit. TPA on biscuit piece was finished utilizing the surface analyzer LR-5K (Lloyd Instruments Ltd, Hampshire, England) with a 5-kg load cell. The accompanying conditions were utilized: $5 \mathrm{~cm}$ square cake cuts on the two sides, an example thickness of 1 in., a $80 \mathrm{~mm}$ distance across roundabout test, a cross head speed of 100 $\mathrm{mm} / \mathrm{min}$, and half example tallness pressure. The information was investigated utilizing Nexygen 4.0 programming (Ametek SAS, Elancourt, France). Utilizing the procedure illustrated in [12], the hardness, stickiness, chewiness, cohesiveness, and springiness of biscuit morsel were estimated.

The boundaries recorded beneath were surveyed by allotting mathematical qualities going from 1 to 10 . Covering tone: $1=$ dull brown/pale brown, 10=brilliant earthy colored Crust shape: 1=level/lopsided, $10=$ typical/even. Disintegrate shading: $1=$ caramel white/brown, $10=$ earthenware white 1 address coarse/exceptionally thick/close, while 10 addresses fine/ordinary. Surface: 1=hard, 10=delicate/delicate and sodden. 1 method unfamiliar/ branny/ unforgiving/ dry, 10 methods normal/no mouth buildup the all-out quality score was determined by joining the scores from the six quality classifications (60). The entirety of the things was served at room temperature, and water was accommodated the specialists to wash their mouths after everything was burned-through.

To prepare muffins beat butter and brown sugar in a separate bowl until fluffy, then add eggs one by one and vanilla essence and beat them with beater. Water chestnut flour was used in the replacement of all-purpose flour. In water chestnut flour add $1 / 4$ teaspoon salt and 1 table spoon baking powder and sieve 23 times, after that mixed dry ingredient with wet ingredient. Filled the cup with mixture and baked in a pre-heated oven at $180^{\circ} \mathrm{C}$ for 20-25 minutes. The baked muffins were cooled at room temperature.

For sensory evaluation muffins were assessed by skilled evaluators who assessed muffins samples for their taste, appearance, color, texture, chewing ability and general satisfactoriness using 9-point hedonic scale. 
SPSS software was used for statistical analysis (version 21). As mentioned, a factorial design was utilized to evaluate data in a totally randomized manner. Data on the chemical and physical properties of muffins were presented as mean standard deviation. To compare the experimental data, the statistical analysis was performed using ANOVA and Duncan's multiple comparison tests in XLSTAT (Addinsoft, New York, NY, USA). P B 0.05 was used as the significance threshold. P B 0.05 was used to assess the correlation between sensory quality of muffins and objective measurements of texture.

\section{Results}

Appearance is a benchmark which provides a knowledge of the food being healthy or not and it has a straight connection with aroma and flavor of the food. Mean values of sensory evaluation of prepared products (muffins) for the appearance feature, amalgamated with chestnut flour. As appearance is the striking feature of a food product, it really performs as the important factor for its achievement. If the appearance of a product or food is unappealing then the customer would never consider the product to taste. Outcomes of the treatment means reflected a remarkable effect statistically Overall, results were statistically significant at $\mathrm{p}<0.05$ and $\alpha 5 \%$ on the appearance especially the $\mathrm{T}_{4}$ and $\mathrm{T}_{5}$ (Fig. 1). Highest mean value was recorded in case of $T_{4}$ (Muffins with chestnut flour, $10 \mathrm{~g}$ ); 7.00 \pm 0.82 and $\mathrm{T}_{5}$ (Muffins with chestnut flour, 12 g); $6.75 \pm 0.96$ whereas intermediate scores were observed in case of other treatments and the lowermost score $(4.5 \pm 2.38)$ was noted in control $\left(\mathrm{T}_{0}\right)$.

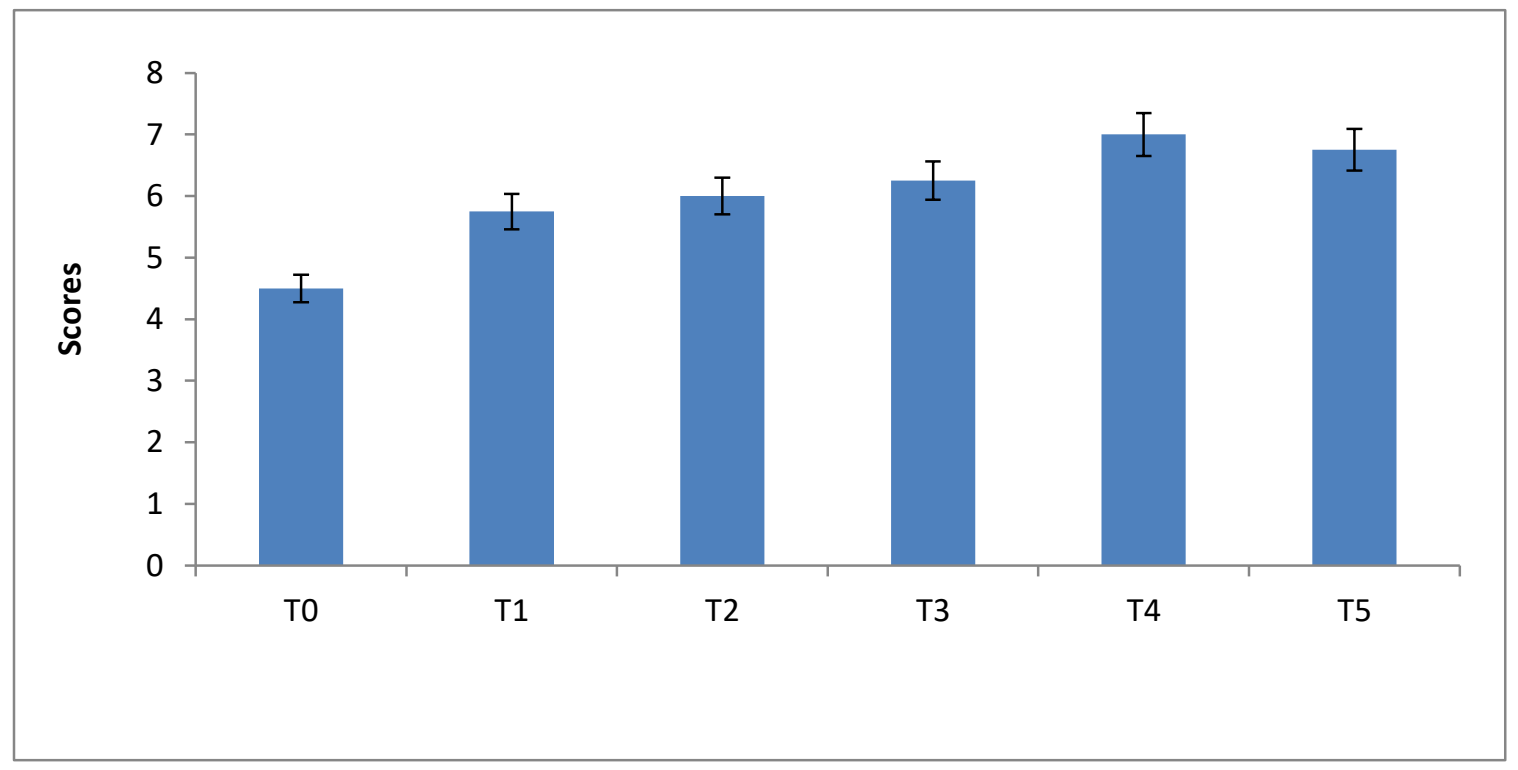

Figure 1. Variation in Appearance

Treatments description (g of Chestnut flour)

$\mathbf{T}_{\mathbf{0}}=$ Control, Muffins with chestnut flour $(0 \mathrm{~g})$

$\mathbf{T}_{\mathbf{1}}=$ Muffins with chestnut flour $(4 \mathrm{~g})$

$\mathbf{T}_{\mathbf{2}}=$ Muffins with chestnut flour $(6 \mathrm{~g})$

$\mathbf{T}_{\mathbf{3}}=$ Muffins with chestnut flour $(8 \mathrm{~g})$

$\mathbf{T}_{4}=$ Muffins with chestnut flour (10 g)

$\mathbf{T}_{\mathbf{5}}=$ Muffins with chestnut flour (12 g) 
Color is also a benchmark which provides an information of the food being healthy or not and it has a direct association with aroma and flavor of the food. Mean values of sensory evaluation of prepared products (muffins) for the color feature, merged with chestnut was indicated in (Fig. 2). As crust color is the prominent characteristics of a food product, it indeed performs as the significant factor for its success. If the crust color of a product or food is unlikeable then the customer would never ponder the product to taste. Findings disclosed that maximum mean value $7.00 \pm 0.82$ was noticed in $\mathrm{T}_{4}$ while lowest score $(6.00 \pm 2.16)$ result was given by $T_{3}$ statistically equal with value control. $\mathrm{T}_{3}$ and $\mathrm{T}_{5}$ were statistically equal with scores of

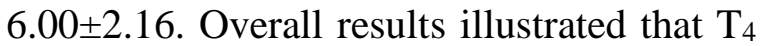
was relatively better than other treatments.

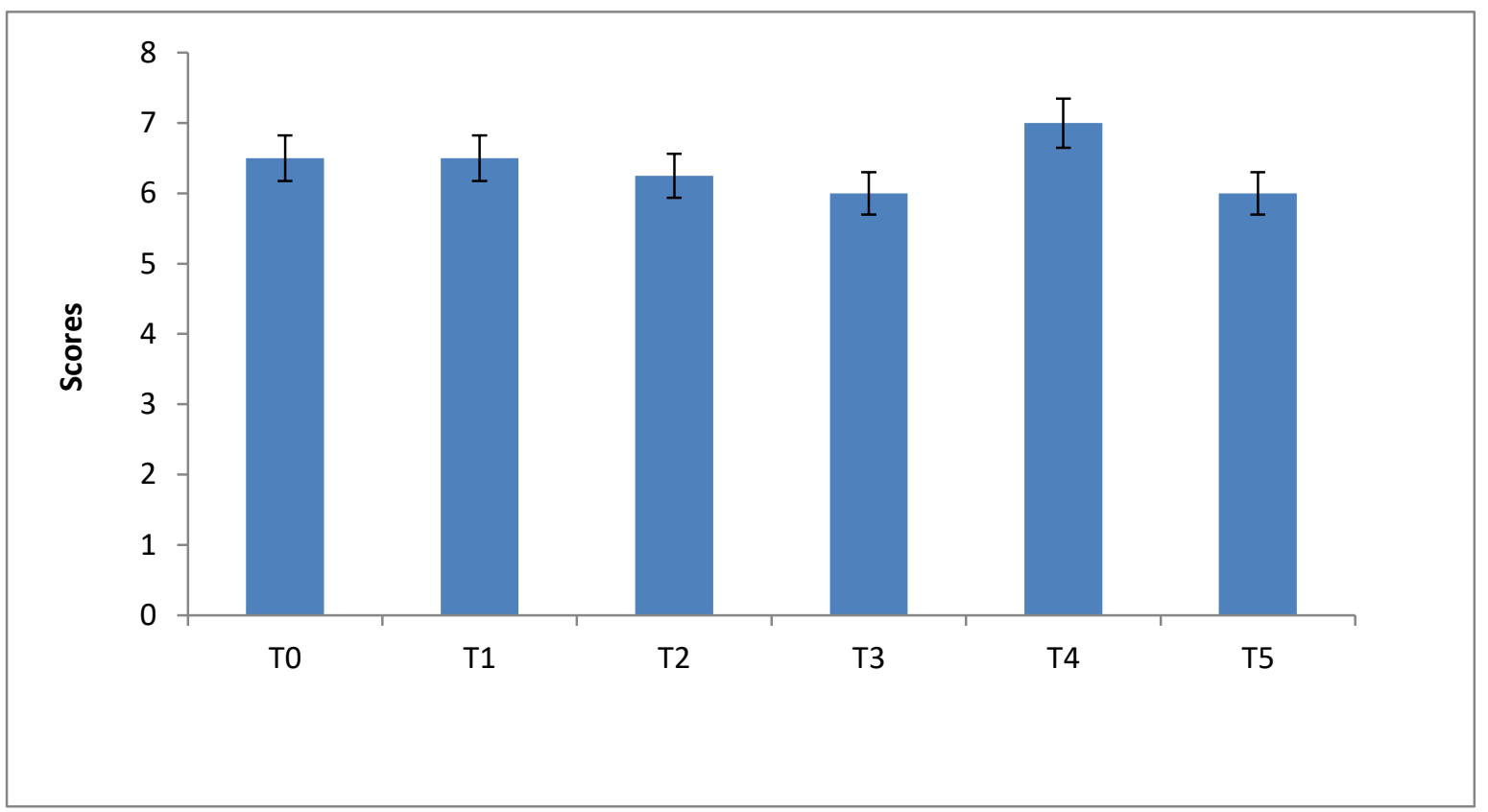

Figure 2. Variation in Color

Texture of the food reveals structural stability of a food product. Outcomes of the treatment means reflected a remarkable effect statistically on the texture of the prepared muffins (Fig. 3). $\mathrm{T}_{4}$ and $\mathrm{T}_{3}$ showed highest mean value $(7.25 \pm 3.10)$ while $T_{1}, T_{2}$ and $T_{5}$ were statistically equal with value of $7.00 \pm 0.82$. Control was the least effective amongst all. Overall, the results showed that all treatments were much more successful than the control (Fig. 3). The decrease in hardness with the addition of chestnut flour might be attributable to the chestnut flour's high sugar content, which could alter starch gelatinization during the frying process, resulting in textural changes. Sugars have been shown to delay starch gelatinization by decreasing water activity and stabilising the amorphous portions of the starch granule through interactions with starch linkages. Fried meals are said to be rich in both calories and fat.

Flavor of the food discloses liking of a food product, governed by aroma and taste and plays a pivotal role in the selection of rejection of commodity by the consumer. Results of the treatment means reflected variation in means values of food product flavor especially the outstanding results in case of $\mathrm{T}_{3}$ (Fig. 4). Highest mean value was 
recorded in case of $T_{5}$ (12 g chestnut flour muffin); while equal results i.e. $7.5 \pm 2.34$ was recorded. In case of $T_{2}$ the value was $7.00 \pm 0.82$. Control was the least effective control treatment $\left(\mathrm{T}_{0}\right)$ gave mean value of 5.25 \pm 2.45 . Overall results depicted the treatments were relatively more effective than the control.

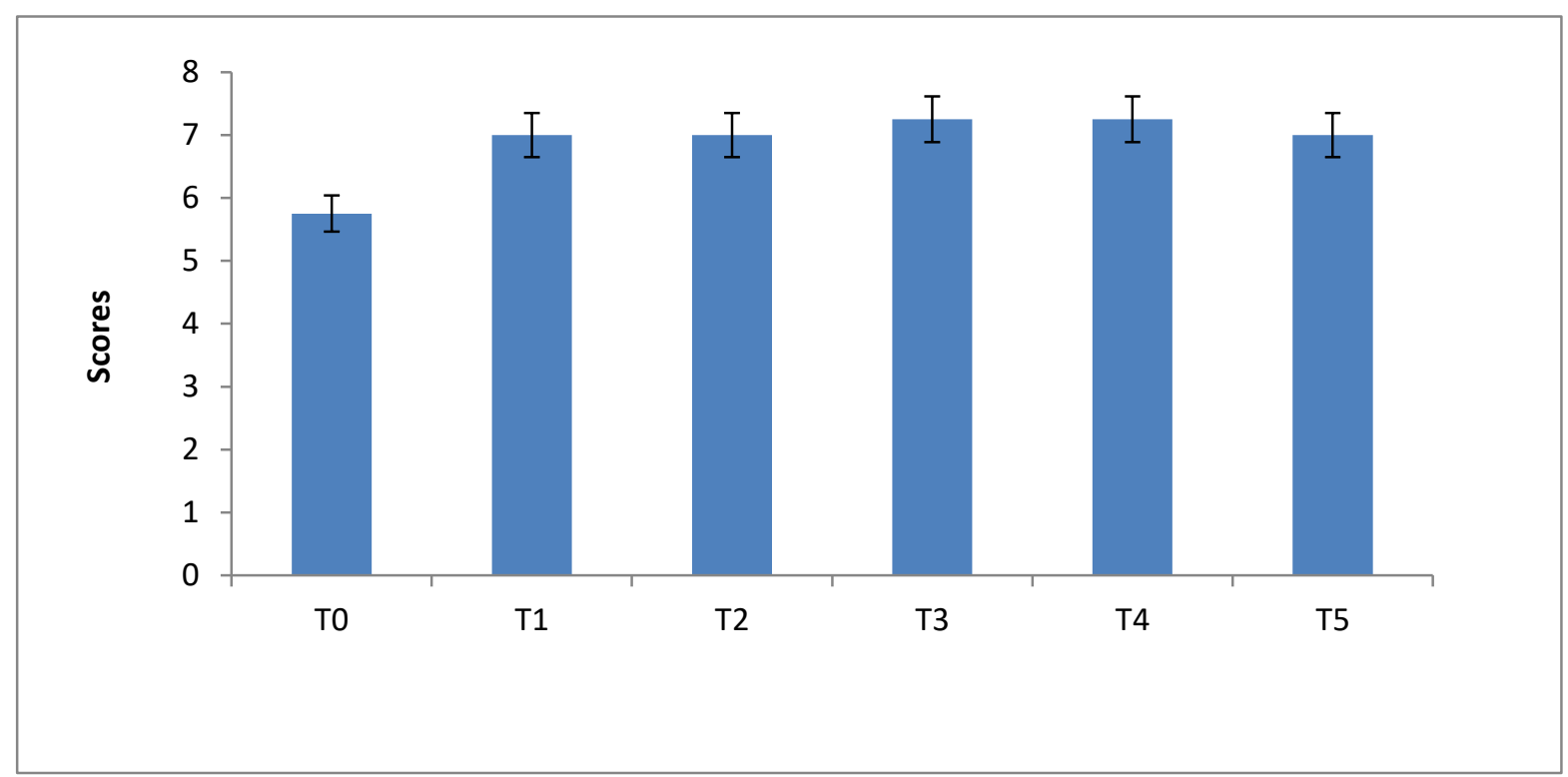

Figure 3. Variation in Texture

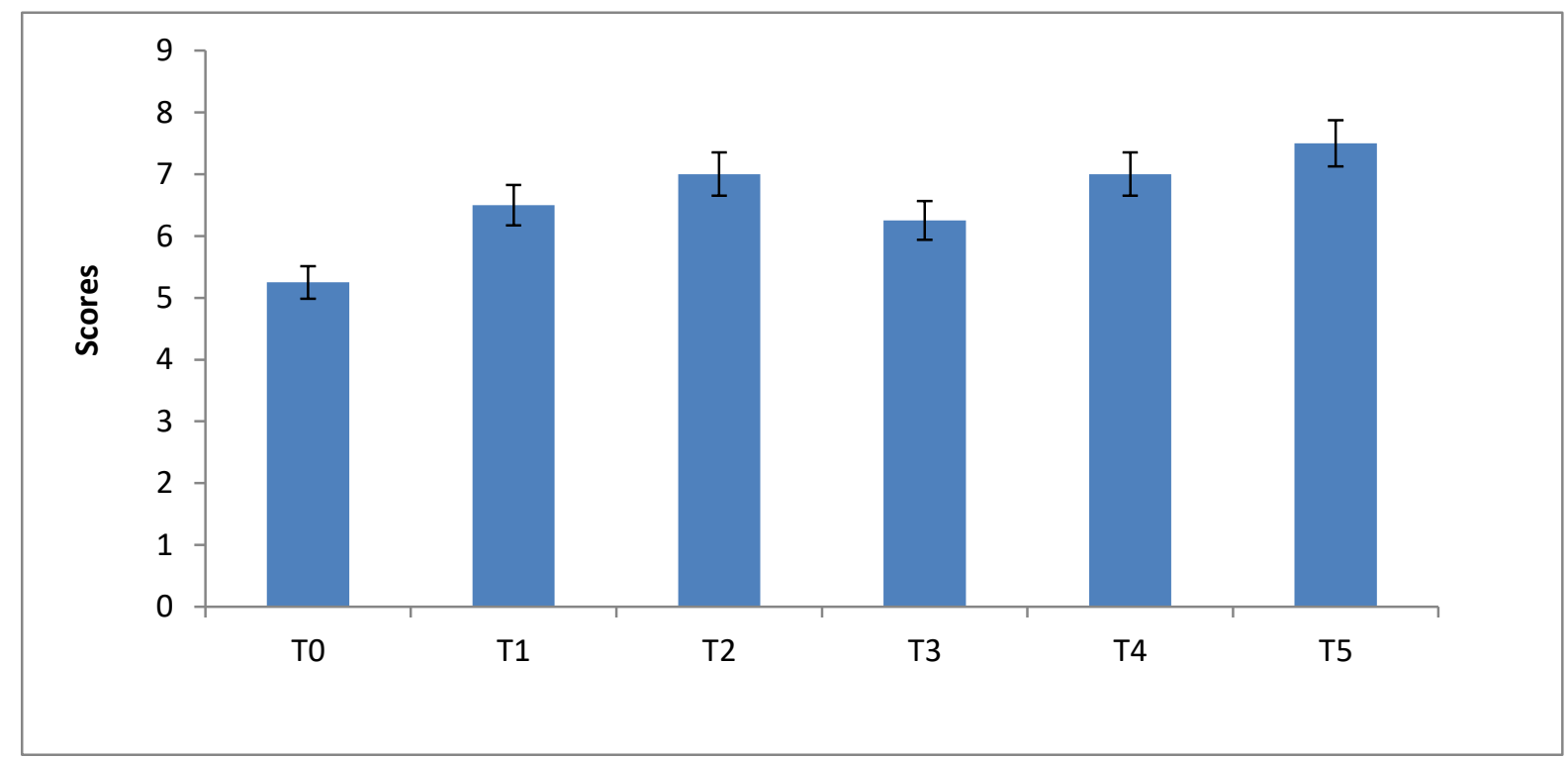

Figure 4. Variation in Flavor

Aroma is also an important featrue of food product and is reflected by a pleasant smell. A food should have a good aroma in order to be smelled and chosen for human consumption otherwise rejected by consumer. Outcomes disclosed that maximum mean value $7.00 \pm 0.82$ was noticed in $\mathrm{T}_{5}$ while relatively lower values were recorded in $\mathrm{T}_{4}, 6.75 \pm 0.96, \mathrm{~T}_{1}$, $6.25 \pm 2.26$ wherease $T_{2}$ equally effective as 
was the $\mathrm{T}_{0}$ (Fig. 5). However, $\mathrm{T}_{3}$ Overall results illustrated that $\mathrm{T}_{3}$ was relatively less effective than other treatments.

Data regarding softness showed that muffins prepared from $\mathrm{T}_{5}$ were softer and attracted the consumer than the rest of all treatments. Treatment $T_{2}$ and $T_{4}$ were statistically equal with value of $6.75 \pm 0.96$. $\mathrm{T}_{1}$ was the next better one with mean softness score of $6.50 \pm 2.27$ slightly greater than control (6.00 \pm 2.16$). T_{3}$ was least effective amongst the all (Fig. 6). Incorporation of chestnut flour turned the muffins in our study by reducing the hardness.

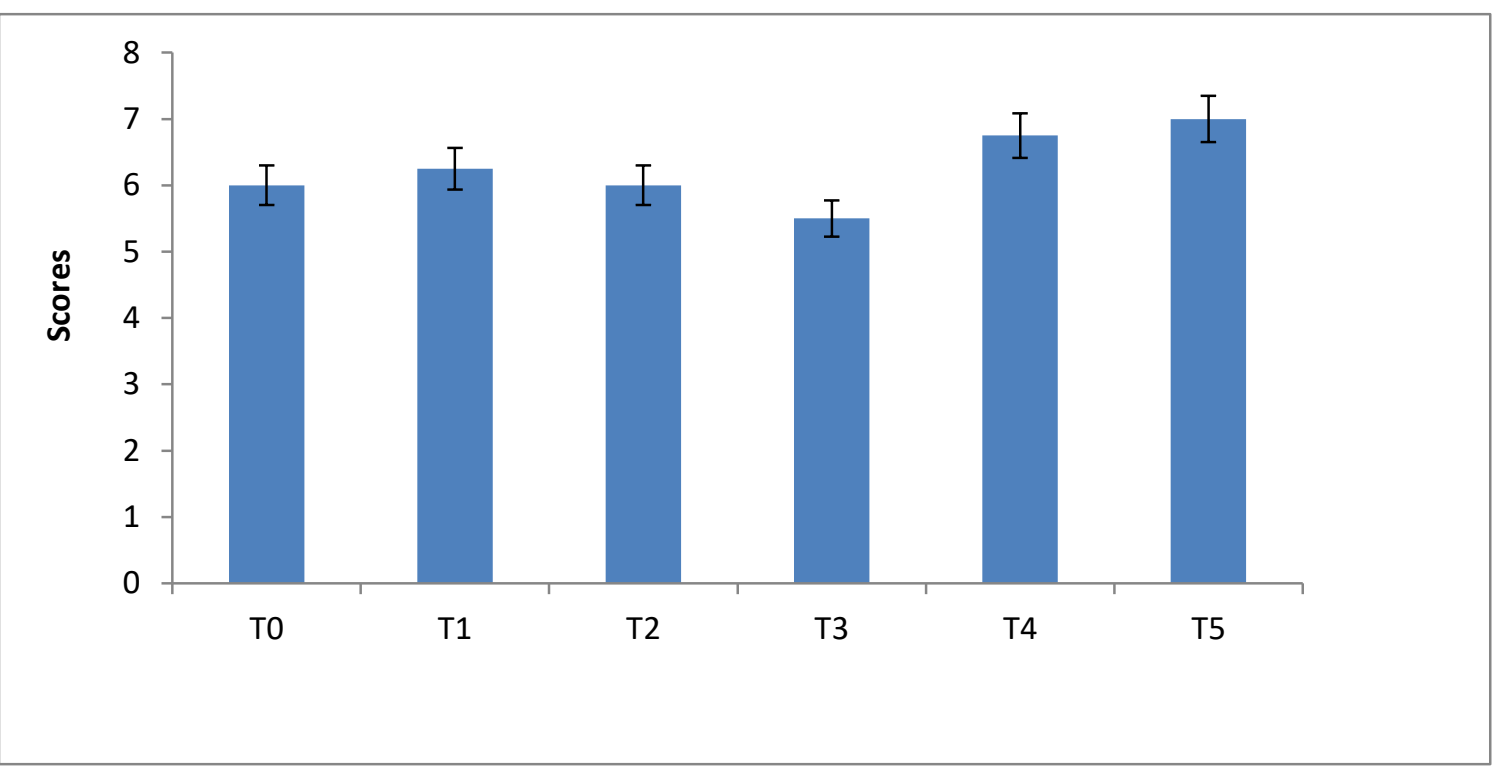

Figure 5. Variation in aroma

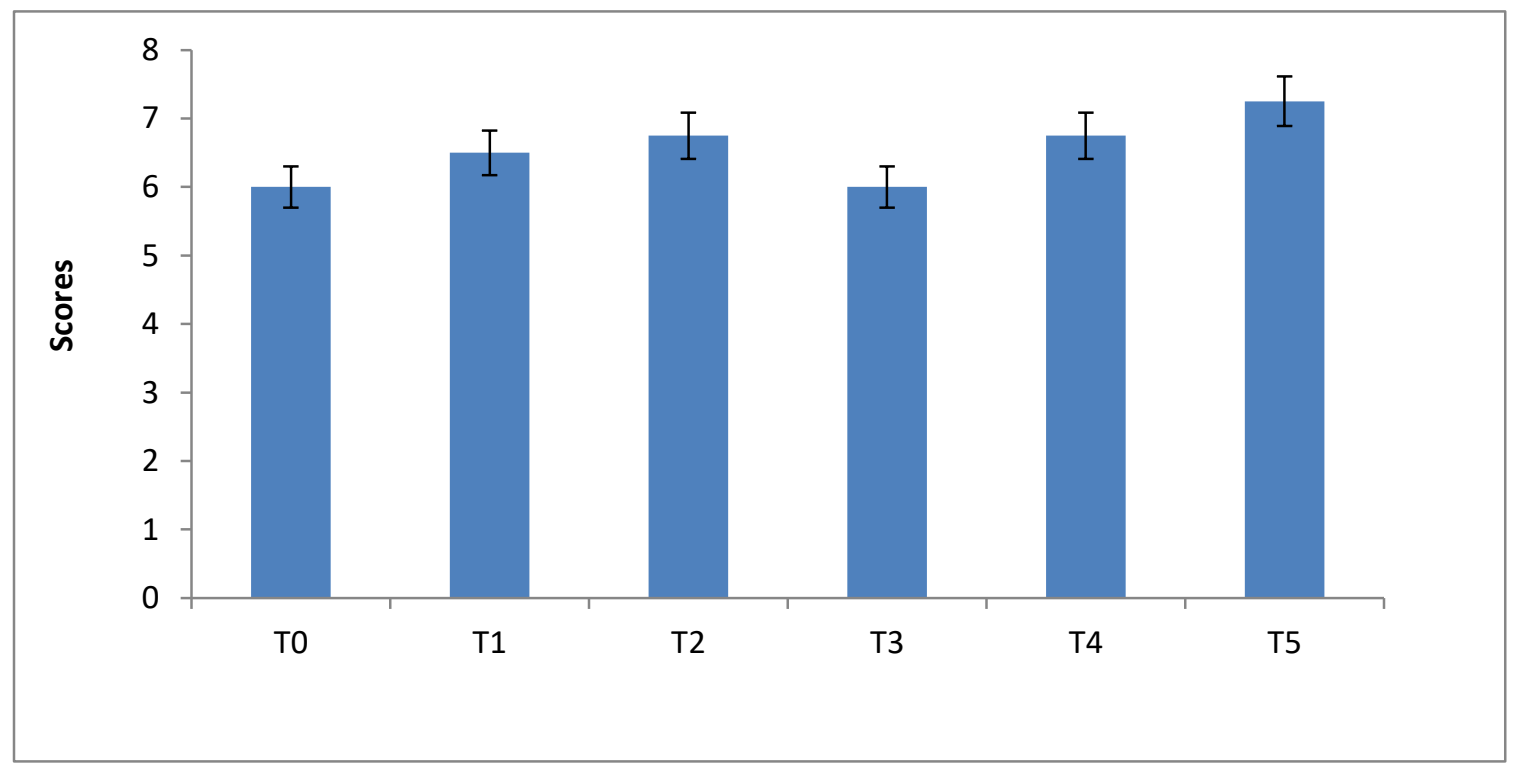

Figure 6. Variation in Softness

The mouthfeel of a food product amalgamated with the samples was affected by the dissimilar concentrations added in the inconstant treatments. Results of the 
treatment means imitated variation in means values of muffins mouthfeel especially the outstanding results in case of $\mathrm{T}_{4}$ (Fig. 7). Highest mean value was recorded in case of $\mathrm{T}_{4} 6.50 \pm 1.43$ followed by the treatment mean of $\mathrm{T}_{3}, 6.00 \pm 2.16$ which was greater than $\mathrm{T}_{1}$ and $\mathrm{T}_{2}$. Control was the least effective control treatment $\left(\mathrm{T}_{0}\right)$ gave mean value of $5.00 \pm 0.06$. Overall results depicted that $\mathrm{T}_{4}$ treatment was the most effective.
After taste is also very important parameter for a food to be selected or rejected. Results of after taste of prepared muffins showed that highest score $(7.00 \pm 0.82) \mathrm{T}_{4}$ was showed by followed by $T_{3}$ while $T_{1}, T_{2}$ and $T_{5}$ were statistically equal with values of $6.25 \pm 2.26$. However, all the treatments were more

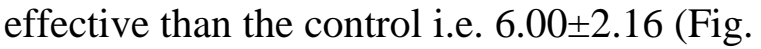
8)..

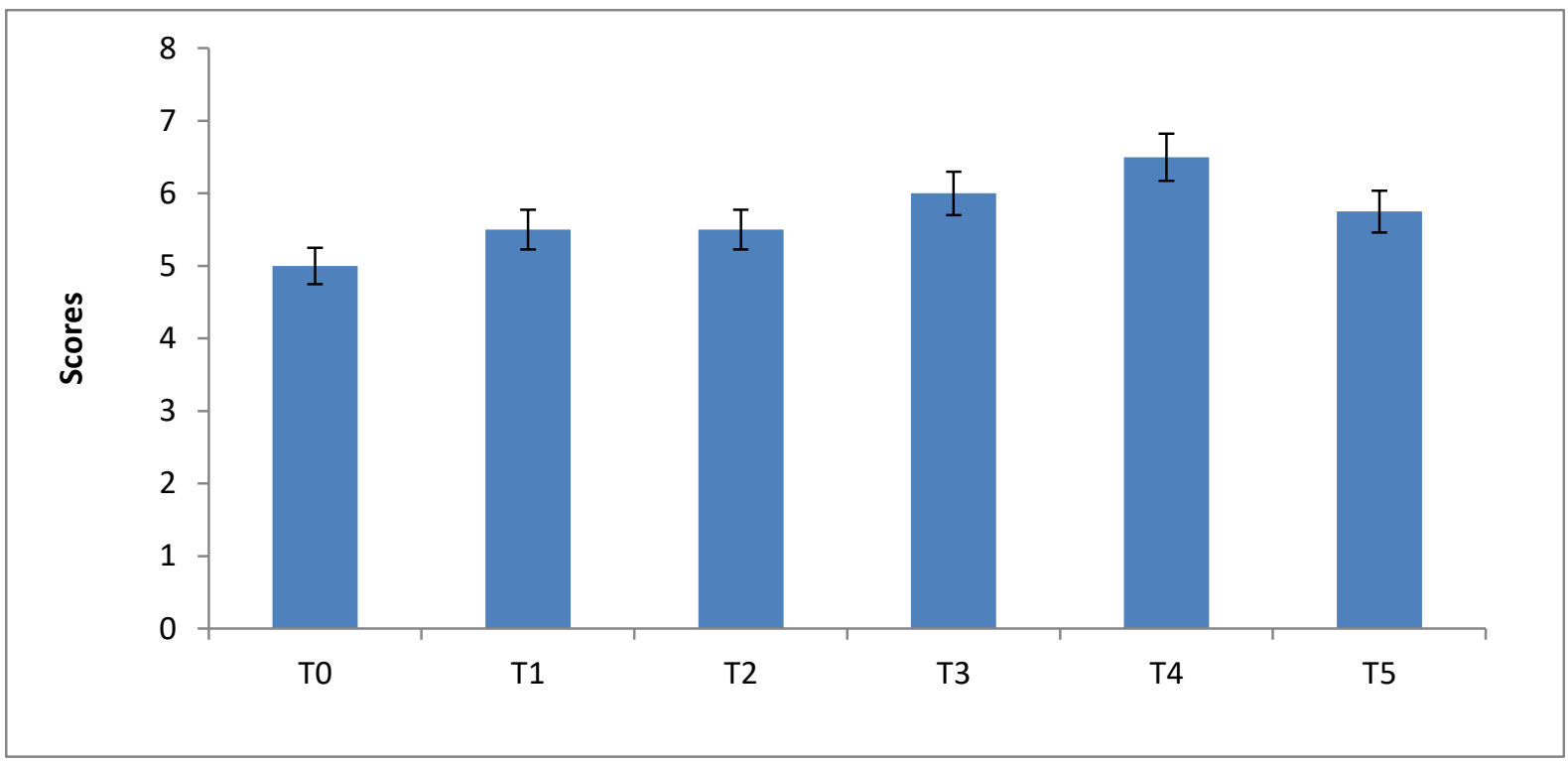

Figure 7. Variation in Mouth feel

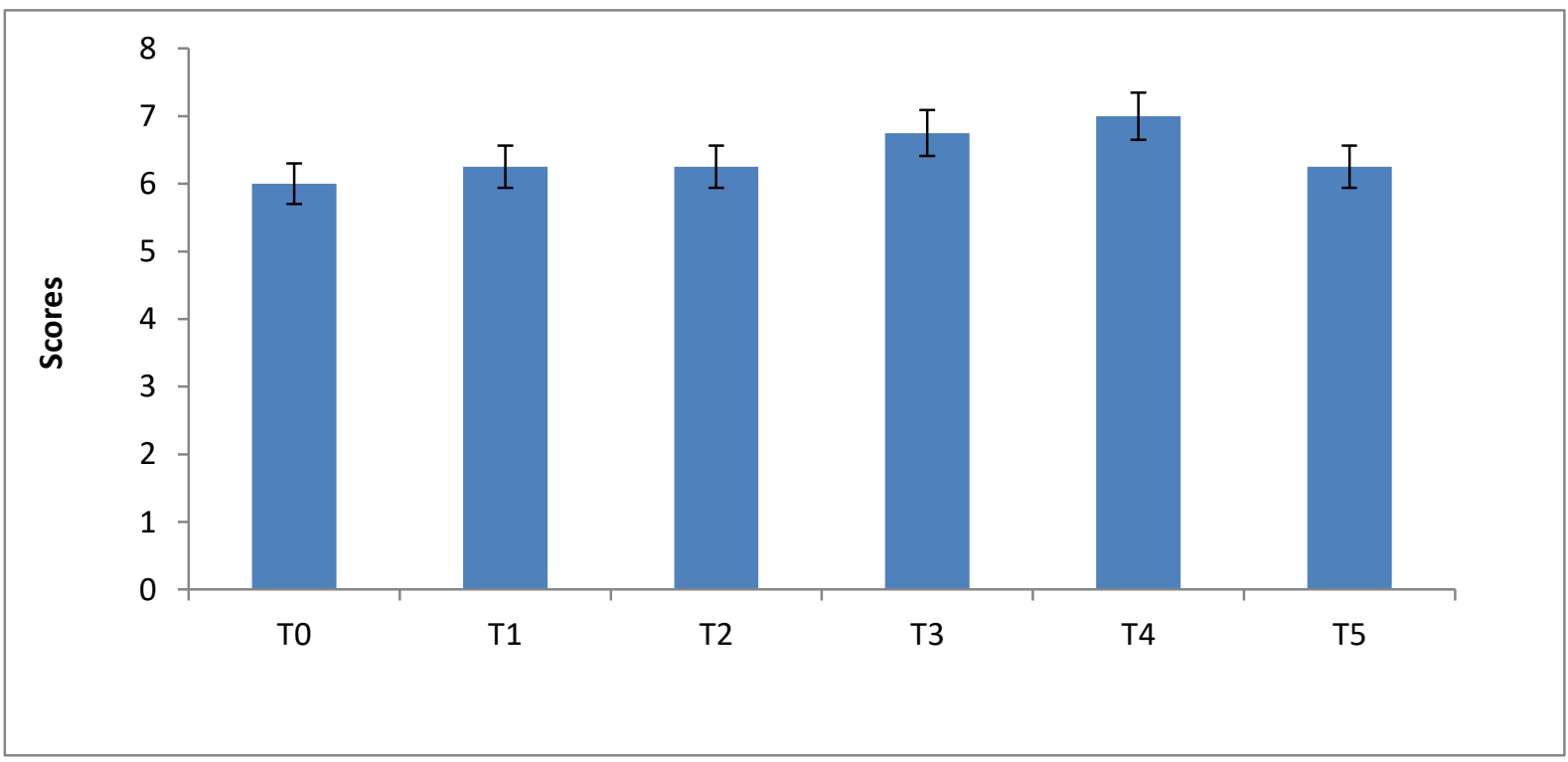

Figure 8. Variation in after taste 
It is decision making stage based about all the other features score of a food product. Results of the treatment means imitated variation in means values of food product overall acceptability specially the outstanding results in case of T3 (Fig. 9 \& Table 1). Highest mean value was recorded in case of $T_{5}, 7.75 \pm 2.76$ followed by the treatment mean of $\mathrm{T}_{4}, 7.25 \pm 2.71$ which was greater than T3, 7.00 \pm 0.82 . Control was the least effective control treatment $\left(\mathrm{T}_{0}\right)$ gave mean value of $6.00 \pm 2.16$. Overall results depicted that $\mathrm{T}_{5}$ was the most effective treatment amongst the all. Overal outcomes rvealed that $T_{5}$ was the most acceptable muffin by consumer among the four prepared products.

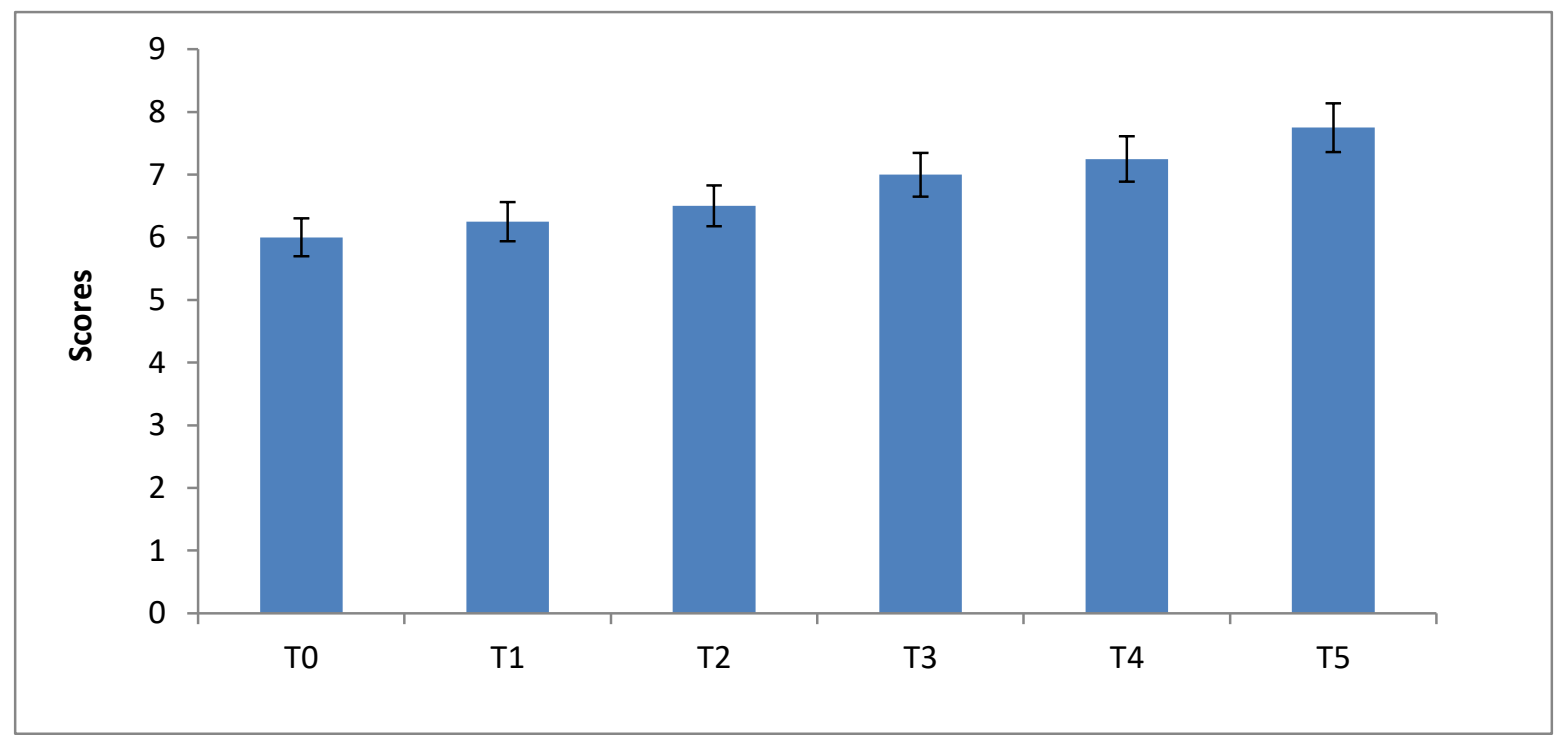

Figure 9. Variation in overall acceptability

Table 1. Variation in sensory attributes

\begin{tabular}{|c|c|c|c|c|c|c|}
\hline Parameters & T0 & T1 & T2 & T3 & T4 & T5 \\
\hline Appearance & $4.5 \pm 0.82$ & $5.75 \pm 0.82$ & $6 \pm 0.75$ & $6.25 \pm 0.82$ & $7 \pm 0.82$ & $6.75 \pm 0.54$ \\
\hline Color & $6.5 \pm 0.76$ & $6.5 \pm 0.82$ & $6.25 \pm 0.52$ & $6 \pm 0.82$ & $7 \pm 0.82$ & $6 \pm 0.75$ \\
\hline Texture & $5.75 \pm 0.91$ & $7 \pm 0.82$ & $7 \pm 0.82$ & $7.25 \pm 0.80$ & $7.25 \pm 0.80$ & $7 \pm 0.82$ \\
\hline Flavor & $5.25 \pm 0.84$ & $6.5 \pm 0.82$ & $7 \pm 0.82$ & $6.25 \pm 0.82$ & $7 \pm 0.82$ & $7.5 \pm 0.81$ \\
\hline Aroma & $6.0 \pm 0.64$ & $6.25 \pm 0.67$ & $6 \pm 0.75$ & $5.5 \pm 0.82$ & $6.75 \pm 0.82$ & $7 \pm 0.82$ \\
\hline Softness & $6.0 \pm 0.64$ & $6.5 \pm 0.82$ & $6.75 \pm 0.54$ & $6 \pm 0.82$ & $6.75 \pm 0.82$ & $7.25 \pm 0.80$ \\
\hline Mouth feel & $6.5 \pm 0.82$ & $5.5 \pm 0.34$ & $5.5 \pm 0.82$ & $6 \pm 0.82$ & $6.5 \pm 0.75$ & $5.75 \pm 0.49$ \\
\hline After taste & $6.4 \pm 0.72$ & $6.25 \pm 0.67$ & $6.25 \pm 0.82$ & $6.75 \pm 0.82$ & $7 \pm 0.82$ & $6.25 \pm 0.82$ \\
\hline Overall acceptability & $6.0 \pm 0.64$ & $6.25 \pm 0.67$ & $6.5 \pm 0.82$ & $7 \pm 0.82$ & $7.25 \pm 0.82$ & $7.75 \pm 0.59$ \\
\hline
\end{tabular}

\section{Discussion}

The present research was executed for the sensory and qualitative evaluation of water chestnut flour muffins. All the research work was performed at optimal laboratory situations. The freshly prepared muffins were positioned on a clean white plates enclosed in transparent sheets and labeled correspondingly on the evaluation day. Our results of augmented appearance attraction with addition of chestnut flour are in line with [13] that assessed the sensory parameters of 
muffins prepared from chestnut flour and noted the improved appearance at relatively higher concentration of chestnut flour addition as was noted in our study with $\mathrm{T}_{4}$ and $T_{5}$. [10] whom checked influence of different ratios of chestnut flour substitution on brown rice flour based snacks and noted that Expansion ratio of snacks is increased while as hardness decreased with progressive increase of chestnut flour. Our findings are consistent with those of $[14,15]$ and are also close to those of [13]. In our study, we found a similar result in treatment T4. Food texture reveals a food product's structural integrity. The abatement in hardness brought about by the expansion of chestnut flour may be ascribed to the high sugar content of the chestnut flour, which could influence starch gelatinization during the browning system, coming about in textural modifications. Sugars have been found to defer starch gelatinization by decreasing water movement and balancing out the undefined districts of the starch granule through cooperations with starch linkages. Seared food sources are viewed as high in calories and fat while additionally adding a specific tone, surface, and flavor to the dish [16]. [14] confirmed the increase in texture of items made from chestnut flour in our investigation. where increased level of incorporated chestnut flour augmented the texture of the prepared products compared to control as was noted in our research work with $\mathrm{T}_{4}$. In our study, addition of chestnut flour augmented the favor of prepared muffins. The similar was noted by [10]. whom evaluated the effect of of different ratios of chestnut flour substitution on brown rice flour based snacks and observed increase in flavor of the prepared products. Results of our study were also supported by [17] whom assessed the performance of chestnut flour in cookies and recorded scores up to 7.9. The results of current study $\left(\mathrm{T}_{5}\right)$ are in line with [18] whom noted increased scores for aroma (up to 7.00) mufifns prepared with increased addition of chestnut flour as compared to those prepared at low concentration of the flour as was noted in our study $\left(\mathrm{T}_{3}\right)$. Results of softness are supported by [10]. who observed that expansion ratio of snacks is increased while as hardness decreased with progressive increase of chestnut flour. [4] discovered similar findings. Who detected an increase in the score of muffins produced with chestnut flour at a significantly higher concentration compared to the low as seen in our T4 study? $[15,17]$ found similar after-taste ratings. The addition of WCF reduced the crispiness of the cookies from 8.5 to 7.9 . Overall, the data showed that T5 was the most effective therapy of all. Overall, the results revealed that T5 was the most popular muffin among the four produced goods. [4] reported that cookies made with various ratios of chestnut flour had a high overall acceptability score. Our findings are similar with those of [10], who investigated the technical and nutritional effects of different percentages of chestnut flour substitution on brown rice flour-based snacks. Pasting properties varied significantly across flour ratios, with larger quantities of chestnut flour resulting in greater pasting capabilities. Color parameters, L, a, and b values of snacks decreased as the amount of chestnut flour increased.

\section{Conclusion}

From the results can be concluded that the use of chestnut flour in gluten-free food market and high dietary-fber containing foods instead of wheat flour by being doped with different additives is increasing the signifcance of itself. Chestnut flour, which is of great signifcance in preparing bakery products for celiac patients, should be produced more and be added to different products.

\section{Authors' contributions}

Conceived and designed the experiments: A Nazir, Performed the experiments: N Itrat, 
Analyzed the data: M Mehboob, Contributed materials/ analysis/ tools: U Ahmad, Wrote the paper: A Nazir \& D Ali.

\section{References}

1. Cencic A \& Chingwaru W (2010). The role of functional foods, nutraceuticals, and food supplements in intestinal health. Nutr 2(6): 611-625.

2. Gao J, Brennan MA, Mason SL \& Brennan CS (2017). Effects of sugar substitution with "Stevianna" on the sensory characteristics of muffins. $J$ of Food Quality.

3. Krishnaiya R, Kasar C \& Gupta S (2016). Influence of water chestnut (Trapa natans) on chemical, rheological, sensory and nutritional characteristics of muffins. $J$ of Food Meas and Charac 10(2): 210-219.

4. Mancebo CM, Rodriguez P \& Gómez M (2016). Assessing rice flour-starch-protein mixtures to produce gluten free sugar-snap cookies. LWT-Food Sci and Technol 67: 127-132.

5. Mir SA, Bosco SJD \& Shah MA (2019). Technological and nutritional properties of gluten-free snacks based on brown rice and chestnut flour. J of the Saudi Soc of Agric Sci 18(1): 89-94.

6. Parekh J \& Chanda S (2007). In vitro antimicrobial activity of Trapa natans $\mathrm{L}$. fruit rind extracted in different solvents. Afr $J$ of Biotechnol 6(6).

7. Puste AM (2004). Agronomic management of wetland crops. Kalyani publishers.

8. Ravi R \& Susheelamma NS (2004). The effect of the concentration of batter made from Chickpea (Cicer arietinum L.) flour on the quality of a deep-fried snack. Inter $J$ of Food Sci \& technol 39(7): 755-762.

9. Razvy MA, Faruk MO \& Hoque MA (2011). Environment friendly antibacterial activity of water chestnut fruits. $J$ of Biodiver and Environ Sci 1(1): 26-34.

10. Romjaun ZZ \& Prakash J (2013). Development and assessment of fibre- enriched muffins. Adv in Food Sci 35(4): 159-165.

11. Saeed M, Raheem MIU, Shakeel A, Aslam HK W, Raza MS, Razzaq Z \& Shoaib M (2015). Effect of water chest nut and apple pomace powder on the quality parameters of cookies. J Glob Innov Agric Soc Sci 3: 142-145.

12. Bourne MC \& MC B (1978). Texture profile analysis.

13. Sarabhai S \& Prabhasankar P (2015). Influence of whey protein concentrate and potato starch on rheological properties and baking performance of Indian water chestnut flour based gluten free cookie dough. LWT-Food Sci and Technol 63(2): 1301-1308.

14. Singh GD, Bawa AS, Singh S \& Saxena DC (2009). Physicochemical, pasting, thermal and morphological characteristics of Indian water chestnut (Trapa natans) starch. Starch-Stärke 61(1): 35-42.

15. Shafi M, Baba WN \& Masoodi FA (2017). Composite flour blends: Influence of particle size of water chestnut flour on nutraceutical potential and quality of Indian flat breads. $J$ of Food Measu and Charac 11(3): 1094-1105.

16. Soong YY, Tan SP, Leong LP \& Henry JK (2014). Total antioxidant capacity and starch digestibility of muffins baked with rice, wheat, oat, corn and barley flour. Food Chem 164: 462-469.

17. Stojceska V, Ainsworth P, Plunkett A, İbanoğlu E \& İbanoğlu S (2008). Cauliflower by-products as a new source of dietary fibre, antioxidants and proteins in cereal based ready-to-eat expanded snacks. J of Food Engin 87(4): 554-563.

18. Sudha ML, Baskaran V \& Leelavathi K (2007). Apple pomace as a source of dietary fiber and polyphenols and its effect on the rheological characteristics and cake making. Food Chem 104(2): 686-692. 